\title{
DOE/BC// $/ 487--8$ \\ IMPROVED OIL RECOVERY IN MISSISSIPPIAN CARBONATE RESERVOIRS \\ OF KANSAS - NEAR TERM -- CLASS 2
}

Cooperative Agreement Number DE-FC22-93BC14987

The University of Kansas Center for Research Inc.

July 1, 1995

RECEIVED

AU6 051998

Budget Period \#1 Duration from 09/18/94 - 09/17/96

OSTI

Budget Period \#2 Duration from 09/18/96 - 09/17/98

DOE Estimate Cost of Project \$3,169,252

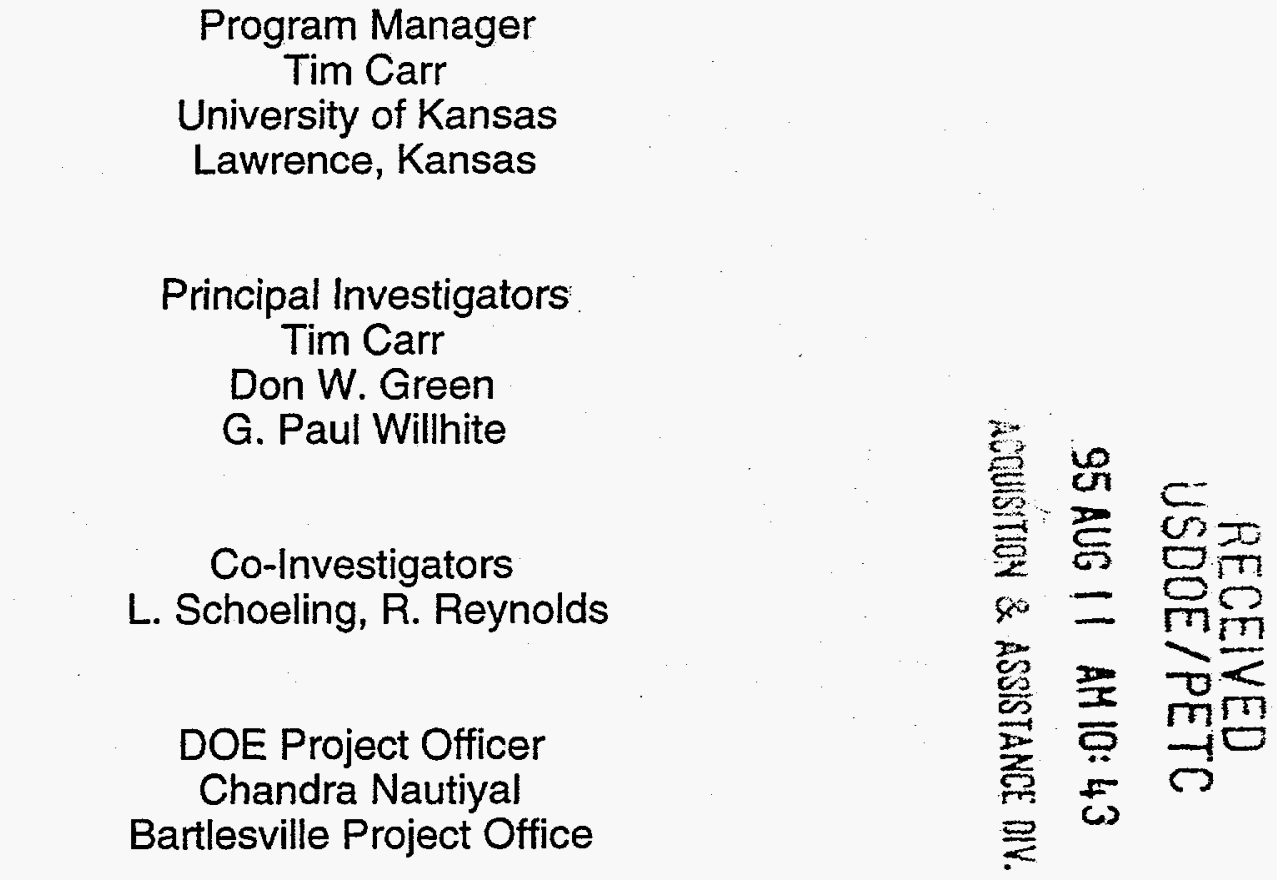

Reporting Period 04/01/95 - 06/30/95

(3rd Quarterly Report)

"U.S./DOE PATENT CLEARANCE IS NOT REQUIRED

PRIOR TO PUBLICATION OF THIS DOCUMENT" 


\section{DISCLAIMER}

Portions of this document may be illegible in electronic image products. Images are produced from the best available original document. 


\section{DISCLAIMER}

This report was prepared as an account of work sponsored by an agency of the United States Government. Neither the United States Government nor any agency thereof, nor any of their employees, makes any warranty, express or implied, or assumes any legal liability or responsibility for the accuracy, completeness, or usefulness of any information, apparatus, product, or process disclosed, or represents that its use would not infringe privately owned rights. Reference herein to any specific commercial product, process, or service by trade name, trademark, manufacturer, or otherwise does not necessarily constitute or imply its endorsement, recommendation, or favoring by the United States Government or any agency thereof. The views and opinions of authors expressed herein do not necessarily state or reflect those of the United States Government or any agency thereof. 


\section{Objectives}

The objective of this project is to demonstrate incremental reserves from Osagian and Meramecian (Mississippian) dolomite reservoirs in western Kansas through application of reservoir characterization to identify areas of unrecovered mobile oil. The project addresses producibility problems in two fields: Specific reservoirs target the Schaben Field in Ness County, Kansas, and the Bindley Field in Hodgeman County, Kansas. The producibility problems to be addressed include inadequate reservoir characterization, drilling and completion design problems, non-optimum recovery efficiency. The results of this project will be disseminated through various technology transfer activities.

\section{Project Status}

The project began in September of 1994, and will run through 1998.

\section{Project Description}

At the Schaben demonstration site, the Kansas team will conduct a field project to demonstrate better approaches to identify bypassed oil within and between reservoir units. The approach will include:

- Advanced integrated reservoir description and characterization, including integration of existing data, and drilling, logging, coring and testing three new wells through the reservoir intervals. Advanced reservoir techniques will include high-resolution core description, petrophysical analysis of pore system attributes, and geostatistical analysis and $3 \mathrm{D}$ visualization of interwell heterogeneity.

- Computer applications will be used to manage, map, and describe the reservoir. Computer simulations will be used to design better recovery processes, and identify potential incremental reserves.

- Comparison of the reservoir geology and field performance of the Schaben Field with the previously described by slightly younger Bindley Field in adjacent Hodgeman, County.

- Drilling of new wells between older wells (infill drilling) to contact missed zones;

- Demonstration of improved reservoir management techniques, and of incremental recovery through potential deepening and recompletion of existing wells and targeted infill drilling.

The project is an effort to make Kansas producers more aware of potentially useful technologies and to demonstrate in actual oil field operations how to apply 
them. For many producers, especially independents, such information is important for continued production. A major emphasis of the Kansas project will be collaboration of University scientists and engineers with the independent producers and service companies operating in the state. An extensive technology transfer effort will be undertaken to inform other operators of the results of the project. In addition to traditional technology transfer methods (e.g., reports;" trade, professional, and technical publications; workshops; and seminars) a public domain relational database and computerized display package will be made available through the Internet and other means of digital access.

\section{Summary of Technical Progress}

General Overview.--Progress is reported for the period from 1 April 1995 to 30 June 1995. Work in this quarter has concentrated on reservoir characterization (Task 1.2), with the initiation of technology transfer (Task 1.3). Difficulties still remain in the drilling of the final two wells. The bulk of work to date has concentrated on Task 1.1. Some preliminary work on reservoir characterization (Task 1.2) has been completed, and related technology transfer has been initiated.

\section{Task I.1 - Acquisition and Consolidation of Available Data (Target Completion Date: 4/2/95). Delayed Completion (9/30/95).}

Summary of work in last quarter.--Acquisition and consolidation of existing geologic and digital log data were complete last quarter. As reservoir analysis progresses, minor quality problems with the digital data are uncovered (e.g., spurious data within a digital log curve). These errors are corrected either manually or sent back to the digitizing contractor. Work is complete on the acquisition of a production data. We will continue to investigate additional sources of production and productivity data (e.g., Kansas Corporation Commission).

After protracted permitting and scheduling problems, the first of three new wells with modern log suites and core data was drilled during the first quarter. The \#4 Moore "B-P" Twin was spuded on 4/25 and completed on 6/13. Daily drilling and completion reports are attached. An excellent core was recovered and described. The core has lead to the development of a new geologic reservoir model for the Schaben Field. The Ritchie Exploration as operator is pushing to expedite the permitting and drilling of the remaining two wells. Subject to hole conditions and tool availability we are still working on running a magnetic resonance imaging $\log (\mathrm{MRI})$ in at least one of the remaining wells.

Summary of planned work for next quarter.-- This task has been delayed by a contentious operator and his use of the permitting process to delay the drilling of the wells. The remaining two wells should be drilled this quarter. 


\section{Task I.2 - Reservoir Characterization (Target Completion Date: 3/3/96).}

Summary of work in last quarter.--The biggest breakthrough was in development of the ability to bin, load, and display well log data from Schaben Field as a 3D "pseudoseismic" volume. The preliminary results were briefly presented at the DOE contractor's meeting. The presentation lead to several contacts concerning possible cooperative work with other DOE contractors. At Schaben we are using the "Pseudoseismic" approach to recognize and map small faults and stratigraphic geometries within the reservoir units.

The core recovered from the \#4 Moore "B-P" Twin has resulted in a modification of our view of the Schaben reservoir and the Mississippian reservoirs of Kansas, in general. If the multi-tiered karst model is valid, numerous vertically and laterally segregated reservoir compartments would be expected. We will continue to work to provide additional data that confirms or modifies this model.

Work continues on petrophysical analysis making use of newly developed analysis package (PfEFFER). PfEFFER stands for "Petrofacies Evaluation of Formations for Engineering Reservoirs".

Engineering analysis and simulation has picked up with the additional of a dedicated research assistant.

Overall, our geologic understanding of the Schaben reservoir has increased significantly over the last quarter.

Summary of planned work for next quarter.-- Analysis of data from the remaining new wells along with development of a descriptive reservoir model will continue. Engineering analysis and initial simulation efforts will be underway. The 3D geologic analysis of the Schaben Field should be nearly complete.

\section{Task I.3 - Technology Transfer (Target Completion Date: 8/4/96).}

Summary of work in last quarter.-- Technology transfer is beginning to ramp up. The presentation at the DOE contractor's conference resulted in several contacts concerning possible cooperative work with other DOE contractors. These contacts and discussions center on application of the "pseudoseismic" approach to other projects. An open-file report on the "pseudoseismic" approach is available over the Internet (http://crude1.kgs.ukans.edu/publication/carr.html). An abstract on the Schaben was submitted to the Platform Carbonates Workshop to be held in Norman, Oklahoma (3/96).

Summary of planned work for next quarter.--Presentations will be prepared for the Oklahoma conference and the AAPG national meeting. We also plan to highlight the Schaben project at the Kansas Geological Survey's booth at the national AAPG meeting. A scientific paper is being prepared on the "pseudoseismic approach". We will continue our work with Kansas operators on application of the technologies developed as part of the Class II project. 
RITCHIE EXPIORATION, INC.

IzSN. Market - Suive laxu

Wichita. Kansas 67an2-1775

\#4 inoore "B-P" Trin

I16-267-375 FAX316-267-:020

$425^{\prime}$ FNI \& 2215' FEI

Section 30-195-21i

Ness County, Kansas

FINAL REPORT

1993 Production Package

API $15-135-23,864$

Duke Rig 1

Field: B. Mathlesen

office: J. Christian

Ref. Well: REI's \#4 Moore "B-P", 150" W of NW NE, Sec, 30-19S-21W

Elevation: $2292^{\prime}$ G.L. $2300^{\prime}$ K.B.

DRILIING REPORT

\begin{tabular}{|c|c|c|}
\hline$S A$ & LE TOPS & \\
\hline anhydrite & $1510^{\prime}(\div 790)$ & +1 \\
\hline B/Anhy & $1540^{\circ}(+760)$ & $T$ \\
\hline eebrex & $\cdot(-1463)$ & 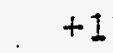 \\
\hline nsing & $3812^{\prime}(-1512)$ & +2 \\
\hline$/ K C$ & $4122^{\prime}(-1822)$ & \\
\hline Pawnee & $4228^{\prime}(-1928)$ & flat \\
\hline ort scott & $4306^{\circ}(-2006)$ & $\dot{+}$ \\
\hline her shale & $4322^{\prime}(-2022)$ & T \\
\hline Ississippl & $4391 \cdot(-2091)$ & -10 \\
\hline $\begin{array}{l}\text { Osage } \\
\text { RTD }\end{array}$ & $\begin{array}{l}4404^{\prime}(-2104) \\
4453^{\prime}(-2153)\end{array}$ & \\
\hline
\end{tabular}

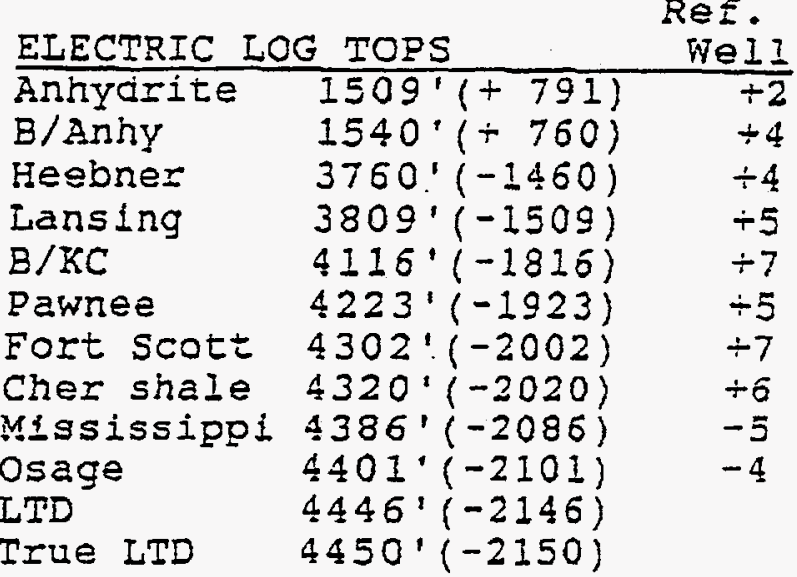

4-25-95 spud at $1: 30$ p.m. Ran 7 joints $\left(304: 74^{\prime}\right)$ of $233^{\prime \prime} 5 / 8^{\prime \prime}$ surface casing set at $315^{\prime}$ with 185 sacks $60 / 40$ pozmix, 28 gel, 3\% CC. Cement circulated. Complete at 8:00 p.m.

4-25-95 Drilling at $560^{\prime}$.

4-27-95 Driling at 1910'.

4-28-95 Drilling at 2790'.

4-29-95 Drilling at $3400^{\prime}$.

4-30-95 Driling at 3970'.

5-1-95 DST $\frac{\| 1}{\pi 1}$ from $4282^{\circ}$ to $4322^{\prime}$ (Eort scott). Recovered 5' mud, no sinow of o11.

IFP: $26-26 \frac{11}{\pi} / 30^{\prime \prime} ;$ ISIP: $28 \% / 30^{\prime \prime} ;$

FFP: $26-26 \frac{\pi}{\pi} / 30^{\prime \prime} ;$ ESIP: $26 \frac{\|}{11} / 30^{\prime \prime}$.

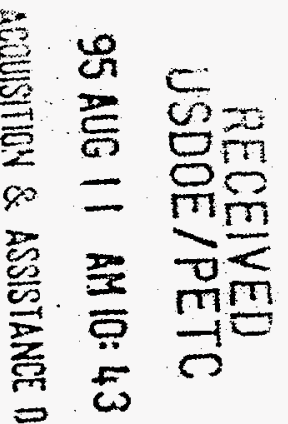

Depth-4370". Preparing to core Mississipioin formation. Cut 9.5' of core, core barrel jammed. Came out of hole. Recovered $9^{\prime}$ of shale and chert rubile. Depth $4380^{\prime}$. 


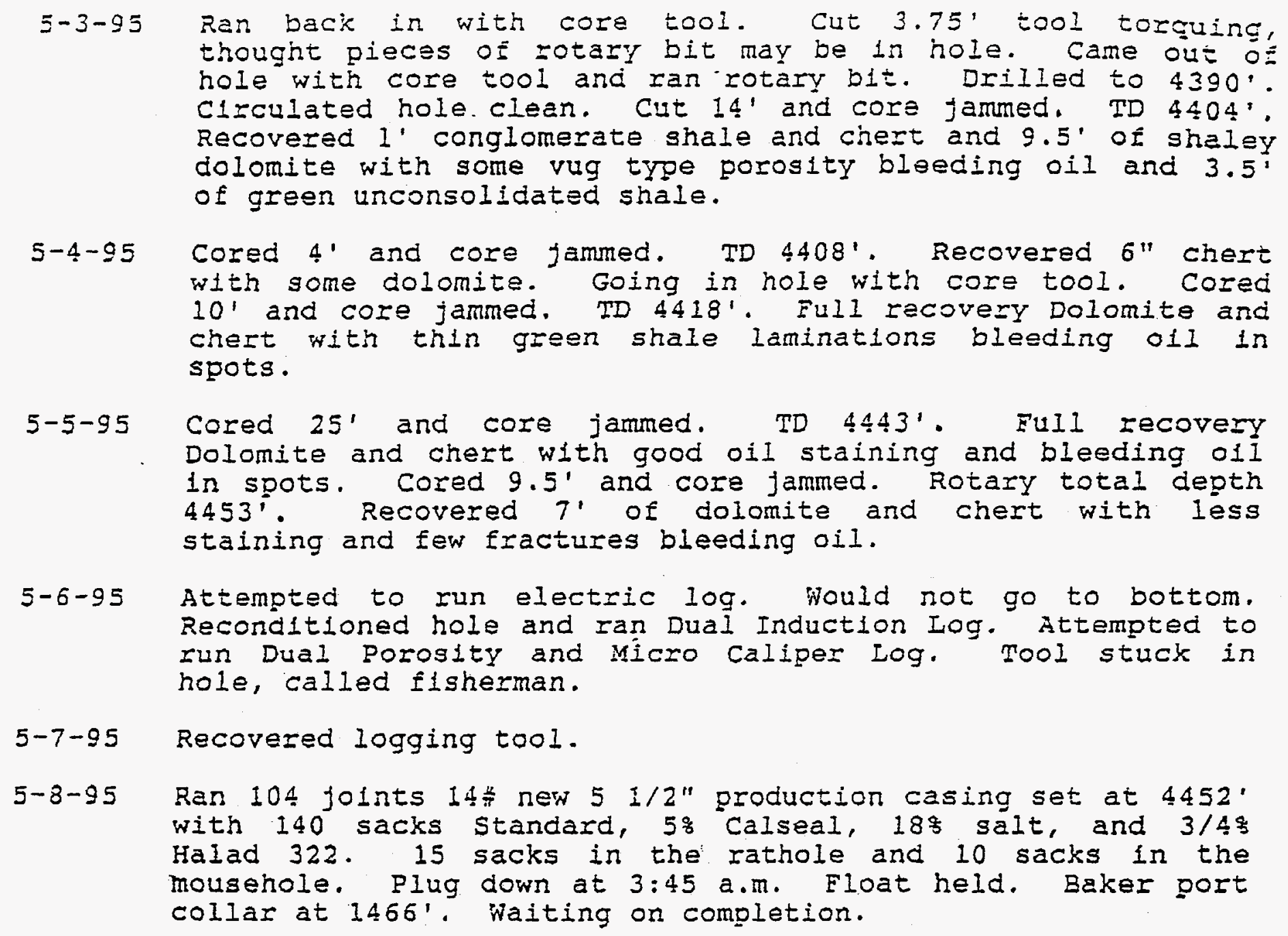


\#4 Moore "B-P" Twin

$425^{\circ}$ FNL \& 2215' FEL

section 30-19S-21W

Ness County, Kansas

1993 Production Package

Field: B. D111s

Office: B. Mathlesen

Elevation: $2292^{\prime}$ G.L. $2300^{\prime}$ K.B.

\section{RITCHIE FXPLORATION, INC}

125 N. Market - Suite 100 )

Wishila, Kat nsiax 67202-1775

$316-267-4375 \quad$ F.4. $\times 310.267-3026$

\section{H1story:}

Set 8 5/8" surface casing at $315^{\prime}$ with 185 sacks. Set new $51 / 2 "$, 14\# production casing at $4452^{\prime}$ with 140 sacks of standard,. 5\% Calseal, $18 \%$ salt, and $3 / 4 \%$ Halad. Baker port collar at $1466^{\prime}$. Distance from $\mathrm{KB}$ to Bradenhead $=9.8^{\circ}$

Length of shoe joint $=32.92^{\circ}$

\section{COMPLETION REPORT}

5-19-95 MIRU double drum. Ran port collar opener and tubing. Found port collar at 1466'. Pressured casing to 1000\#. Opened port collar and cemented with 257 sacks $65 / 35$ poz, $6 \%$ gel, and 1/4\# Flocele. Cement circulated. No KCC man on location. Received verbal permission from Richard Lacey with KCC. Casing pressured OK. Washed out, ran five joints and washed out. Pulled tubing and opener. SDOWE.

5-22-95 Ran 4 7/8" bit and tubing. Hit insert at 4416'. Drilied wiper plug, insert, and 24' of cement. TD at $4440^{\prime}$. Circulated hole clean. Started out of hole with tubing and bit because of bad-weather. Got 25 joints out, cellar caving in. SDON.

5-25-95 Backhoe filled in cellar. Finished pulling tubing and bit. SDON.

5-30-95 Rigged up BPB Wireline. Logged well. SDON.

6-1-95 Swabbed $51 / 2^{\prime \prime}$ casing down to $2800^{\circ}$. SDON.

6-2-95 Finished swabbing down. Swabbed down to 4433' and loaded hole w1th 10 barrels lease water. Perforated from 4401' to $4403^{\prime}$ with 3 SSB per Loot. Swabbed down to $4385^{\prime}$ and recovered 7.09 barrels, Swab tested from $4385^{\prime}$ :

Hour Recovered

$30 \mathrm{~min} \quad 2.92$ bbls, $100 \%$ water

1 hour $\quad 1.23 \mathrm{bbls}, 100 \%$ water

SDOWE. 
\#4 Moore "B-P" Twin

Page 2

6-3-95 Fluld level at 3925', 475' of fillup. Swabbed down, oil with trace of water on bottom. Swabbed down to $4385^{\prime}$ recovered 10.85 barrels o1l. Swab tested from 4385':

$\begin{array}{ll}\text { Hour } & \text { Recovered } \\ 30 \text { min } & \text { Dry } \\ 1 \text { hour } & 0.41 \text { bbls, dirty water w/trace oil } \\ 30 \text { min } & \text { Dry } \\ 2 \text { hours } & 0.25 \text { bbls, } 168 \text { oil } \\ 3 \text { hours } & 5 \text { ' fluid, dirty water } \\ 4 \text { hours } & 5 ' \text { fluid, dirty water }\end{array}$

SDON.

6-5-95 Fluid level at 4250', 150. of fillup. Swabbed down to 4385', all oil. Ran $47 / 8^{\prime \prime}$ bit and tubling, cut $4.5^{\prime}$. Cement to $4444.5^{\circ}, 4.5^{\prime}$ of cement stili in shoe joint. pulled tubling and bit. Swabbed down to $4025^{\prime}$. Perforated 18. below insert collars at $4428.5^{\prime}$ to $4431.5^{\circ}$, three shots per foot, 10 shots SSB. TD at $4439^{\circ}$. Swabbed down to $4385^{\prime}$ and recovered nine barrels with show of oil. SDON.

6-7-95 Fluid level at 3450' from surface, 950' of fillup. Swabbed down to $4400^{\prime}, 105^{\prime}$ oil on top. Recovered 24.63 barrels on swab down. Swab tested from 4400':

Hour Recovered

$30 \mathrm{~m} 1 \mathrm{n} \quad 0.83 \mathrm{bbls}$, show of oil

Tested from 4439 :

$\begin{array}{ll}1 \text { hour } & 1.67 \mathrm{bbls}, \text { show of oil } \\ 30 \text { min } & 1.25 \mathrm{bbls,} \text { show of oil } \\ 2 \text { hours } & 0.83 \mathrm{bbls}, \text { show of oil }\end{array}$

Ran $8^{\prime}$ sub, packer, and tubing. Set packer at $4424^{\prime}$. Swabbed down, fluid level at $3850^{\circ}, 575^{\circ}$ of fillup. Swabbed down to $4424^{\prime}$ and recovered 3.50 barrels, show of o1l. Swab tested from $4424^{\prime}$ :

$\begin{array}{ll}\text { Hour } & \text { Recovered } \\ 30 \mathrm{~min} & 0.83 \mathrm{bbls}, 100 \% \text { water } \\ 1 \text { hour } & 0.83 \mathrm{bbls}, 1008 \text { water }\end{array}$

6-8-95 Fluid level at 2050' from surface, 2375' f1llup, 100\% water. Pulled tubing and packer. Ran Baker cement retainer and set at $44^{\prime} 9^{\prime}, 15^{\circ} 5^{\circ}$ from TD. Took injection rate: $1 / 2$ barrel per minute at $800 \#$. Mixed 50 sacks common cement and squeezed perforations at $4434^{\prime}-4437^{\prime}, 16$ sacks in formation 1000\#. pulled out retainer and washed cement out of tubing. SDON. 
\#4 Moore "B-p" Twin

Page 3

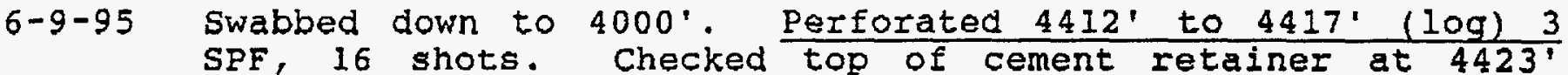
(log) 4429' (tubing tally). Ran packer and tubing. Set packer at $4407^{\prime}$. Swabbed down to $4403^{\prime}$ and recovered 1.50 barrels. Swab tested:

$\begin{array}{ll}\text { Hour } & \text { Recovered } \\ 30 \text { min } & \text { Dry } \\ 1 \text { hour } & 0.50 \mathrm{bbls}, \text { muddy water }\end{array}$

SDOWE.

6-12-95 Fluid level at 2700' from surface, 1710' fillup, 150' oil on top, 8.5\%. Swabbed down to 4400' and recovered $10.02 \mathrm{bbls.}$ Swab tested from $4400^{\prime}$ :

$\begin{array}{ll}\text { Hour } & \text { Recovered } \\ 30 \text { min } & \text { Dry } \\ 1 \text { hour } & \text { Dry } \\ 2 \text { hours } & 0.83 \text { bbls, } 11 \% \text { o } 11 \\ 3 \text { hours } & \text { Dry }\end{array}$

Acidized with 250 gallons $7.5 \%$ INS double FE. Feeding $200 \#$ at $1 / 4$ barrel per minute. With 2.5 barrels acid in, 0 \# at $1 / 4$ barrels per minute. Treated at that rate. ISIP $0 \#$. Instant vacuum. Total load 32.5 barrels. Let set 15 minutes. Swabbed down, fluid level at 475'. Swabbed down to $4400^{\prime}$ and recovered 32.98 barrels. Last pull show of oll. Tested four pulls per hour from 4400':

$\begin{array}{cl}\text { Hour } & \text { Recovered } \\ 1 & 16.28 \text { bbls, } 23 \% \text { o1l } \\ 2 & 14.20 \text { bbls, } 23 \% \text { oil } \\ 3 & 15.44 \text { bbls, } 23 \% \text { oil } \\ 4 & 14.20 \text { bbls, } 23 \% \text { oil }\end{array}$

SDON .

6-13-95 Fluld level at 1500' from surface, 2900' of fillup, 425' oil on top. Pulled tubing and packer. Ran 11' mud anchor set at $4417 ; 51 / 2{ }^{\prime \prime} \times 2$ 1/2" anchor catcher set at $4403^{\prime}$; $1.10^{\prime}$ seating nipple set at $4402^{\prime} ; 141$ joints of $27 / 8^{\prime \prime}$ tubing; $6^{\prime}, 6^{\prime}, 8^{\prime} \times 2$ 7/8" tubing sub. Set anchor with 18,000 over. SDON.

6-14-95 Ran 2 1/2" X 2" X 14" RWT pump with 4' plunger and double valve, 4 - sinker bars, 100 - 3/4" rods, 72 - $7 / 8$ " rods, $8^{\circ}$ \& $6^{\prime}$ pony rods, and $11^{\prime \prime} \times 22^{\prime}$ polish rod with 10 ' iner. RDMO.

6-19-95 Laid lead line and hooked up wellhead.

6-21-95 set pumping unit. Laid electric line. set motor. put well on production. 